\title{
Personality Patterns in Familiar and Delinquency Violence in Mexican Men
}

\author{
Amada Ampudia Rueda ${ }^{1, ~ *, ~ G u a d a l u p e ~ S a ́ n c h e z ~ C r e s p o ², ~ F e r n a n d o ~ J i m e ́ n e z ~ G o ́ m e z ~}$ \\ ${ }^{1}$ Faculty of Psychology, National Autonomous University of Mexico (UNAM), México, Russia \\ ${ }^{2}$ Faculty of Psychology, University of Salamanca, Salamanca, Spanish
}

Email address:

amada@servidor.unam.mx (A. A. Rueda)

${ }^{*}$ Corresponding author

\section{To cite this article:}

Amada Ampudia Rueda, Guadalupe Sánchez Crespo, Fernando Jiménez Gómez. Personality Patterns in Familiar and Delinquency Violence in Mexican Men. Psychology and Behavioral Sciences. Vol. 8, No. 2, 2019, pp. 38-44. doi: 10.11648/j.pbs.20190802.12

Received: March 19, 2019; Accepted: April 29, 2019; Published: June 4, 2019

\begin{abstract}
The objective of this study was to examine personality patterns of aggressive and violent behaviors in the Minnesota Multiphasic Personality Inventory (MMPI-2) scales data obtained from homicide and domestic violence offenders. A group of homicide and domestic violence offenders were administered the test to identify differences and causes. Method 140 subjects participated in this study. We divided them into two groups of 70 incarcerated offenders each based on the cause of their arrest: homicide and domestic violence. Inmates were sampled by non-probability quota sampling, and voluntarily completed the Inventory after giving informed consent. Results: By applying the parametric Student's $t$-test to the scales and using Cohen's d, the effect size of identified differences was obtained. High scores in some scales suggesting differences in expression of aggression between groups were observed. Homicide offenders expressed more openly emotions of aggression, hostility, and anger, while domestic violence perpetrators tend to deny any such factors in their behavior. Both groups showed emotional deviation associated with their offenses. Conclusions: The MMPI-2 has been proved to detect behavior patterns of offenders and their reluctance to readapt to civil society. An interesting matter can be highlighted: Given the conditions in Mexican correctional facilities, currently offenders overall are not motivated enough to reintegrate into social life, having expressed reactions of aggression-related behaviors.
\end{abstract}

Keywords: Personality, Crime, Aggression, Violence, Family

\section{Introduction}

Aggressive and violent behavior is an actual problem in our society, with serious psychological, social, and economic effects. Even if angry emotions and aggressive behaviors can occur as part of the human experience, there are surely particular characteristics that are retrieved from social setting and groups in which they present. However, discussing aggression and violence is complex due to the multiple nonpatterned ways in which they occur.

Physically, they can present as a battle of explicit bodily manifestations. Emotionally, fury or rage can be manifested through facial expression and gestures or change in voice pitch and volume. Cognitively, they can be externalized as destructive fantasies, or persecution or self-persecution thoughts. Socially, they form a frame in which, one way or the other, specific aggressiveness arises [1,2]. The problem is when an individual fails to identify or deal with an aggression-inducing situation, which once turned into an "angry outburst" can lead to serious psychological disorders (anxiety, phobias, obsession, severe depression, etc.) or direct violence (assault, homicide, suicide, etc).

While identifying factors of aggressive and violent behavior is difficult, greater difficulty is entailed when identifying causes or reasons of abuse, or what is specifically different between people who assault and people who do not, or whether or not, a biopsychosociocultural model of aggression and violence patterns can be found. These are only some questions about the situation of men showing aggressive and violent behaviors, most of which have rarely been analyzed, despite being relevant to our society [3].

From a psychological assessment approach of the different needs of violence perpetrators (whether emotional, cognitive, 
mental health, inmate classification), the use of the MMPI-2 in correctional settings has a long history [4]: The original MMPI [5] has been used in criminal justice and corrections for over 60 years.

In the early 1940s, before the original MMPI was completed, used the scales that were then available to assess the personality characteristics of women; and patters of adolescent girls, to delinquents and nondelinquents [6]; and shortly after its publication, applied it to male and female State prisoners and compare with students [7]. The original MMPI and its successors, MMPI-2 and MMPI-A, have been used with adult criminals and delinquents ever since. In the early 1950s, investigated the ability of the original MMPI to forecast subsequent delinquency and the adolescent personality and behavior [8]. In the early 1970s, Megargee empirically derived an MMPI-based classification system for criminal offenders using cluster analysis as a statistical method [9, 10]. This system has been the subject of numerous studies that have demonstrated its reliability and utility in criminal justice assessments. After the MMPI-2 was published, the original MMPI-based classification system was revised so it could be used with offenders in probation, parole, corrections, and forensic mental health settings [11, 12]. published a special report including statements and critical items specifically designed for corrections, along with the 10 Megargee profile types and the MMPI-2 data that have proved useful, not without controversy, in the justice setting [13].

Correctional population presents a set of distinctive features from any other kind of population. Identifies four fundamental features: the number of cases, the degree of legal accountability required, the nature of the offender population, and the consequent need to maintain security [13]. A portion of the newly incarcerated offenders must be screened for mental illness, developmental disabilities, their potential for dangerous or violent behavior, alcohol and substance abuse, etc., after which it must determine which facilities and programs are best suited to their needs. Later, in jurisdictions in which parole is an option, it must be determined if, when, and under what conditions those imprisoned should be released.

Many offenders are emotionally disturbed or mentally ill. A special report issued by The Bureau of Justice Statistics (BJS) recently reported that $283,800(16 \%)$ of the state and federal adult prisoners could be considered mentally ill, and another $15 \%$ to $20 \%$ require mental health services or interventions at some time during their incarceration [14]. In addition to those with emotional disturbances, many have histories of and require treatment for alcohol or substance abuse [14-17]. Along with factors such as age, gender, education, and criminal offense, each prisoner's psychological condition and personality characteristics should play an important role in these management decisions and treatment plans.

It emphasizes that assessment in correctional facilities must focus essentially on three issues: mental health screening, risk assessment, and (management and treatment) needs assessment [18]. It is evident that the MMPI-2 is not quite the technique to solve all these issues, but it is one of the most adequate, reliable techniques used to detect mental disorders, even in incarcerated offenders who try to malinger or deceive the assessor. However, we must point out that the MMPI-2 does not include the most appropriate variables that make it the most adequate technique for recidivism and violence risk assessment. For general personality assessment, and aggressive or violent behavior likelihood or proneness, the MMPI-2 does include a set of variables that may provide relevant data [19].

Needs assessment includes psychological appraisals to identify what each offender needs, how they can adjust and benefit from specific tasks, as well as cognitive and motivational assessments for educational programming or training offered by the correctional facility to help them cope with incarceration and be trained for their reintegration. Based on their MMPI-2 profiles, classification system for incarcerated offenders suggest 10 different types (Able, Baker, Charlie, Delta, Easy, Foxtrot, George, How, Item, and Jupiter) who can adjust to prison and programs offered [12].

The MMPI-2 includes a set of variables that can detect possible aggression reactions that persons may exhibit: Despite the difficulties inherent in predicting violent acts through personality instruments, some researchers have attempted to correlate score results in the MMPI scales developed by Hathaway and McKinley to aggressive and antisocial behavior [20]. Since the 1940s, the MMPI has been considered as an efficient instrument for mental health screening and personality assessment in individuals subject to criminal investigation or assessment for different correctional functions $[21,22,9,4,18]$. Nevertheless, we must ask which scales are best suited to identify violence risk. Jones, Beidleman, and Fowler conducted a study using discriminant analysis of code-types that allowed them to obtain the scales that contributed most to prediction of violent behavior: $\mathrm{F}$ (Infrequency), $\mathrm{Pa}$ (Paranoia), $\mathrm{Pt}$ (Psychasthenia), and Sc (Schizophrenia), correctly classifying $72.9 \%$ of violent and $80.6 \%$ of non-violent inmates [23]. In turn Boscan et al.'s study with Mexican offenders and non-offenders that were administered the MMPI-2 found, along with $\mathrm{F}$ (Infrequency) and Sc (Schizophrenia), the MacAndrew Alcoholism scale (Mac-R) [24].

The study by Megargee, Mercer, and Carbonell with male and female offenders overlaps in the scales of Infrequency (F), Psychopathic Deviate (Pd), Paranoia (Pa), and Hypomania (Ma), along with MacAndrew Alcoholism Scale (Mac-R), Antisocial Practices (ASP), and Addiction Admission Scale (APS) among women [25]. Also, Pa (Paranoia), Pt (Psychasthenia), Sc (Schizophrenia), Ma (Hypomania), and F (Infrequency) were highlighted by researchers as showing elevations among violent individuals [26-28].

The objective of this study was to examine personality patterns of aggressive and violent behaviors in the MMPI-2 scales data obtained from homicide offenders and domestic 
violence offenders.

\section{Method}

\subsection{Participants}

140 inmates from a male Social Readaptation Center were divided into two groups: the homicide group $(\mathrm{n}=70$; median age $=28 ; \mathrm{SD}=4.136)$; and the domestic violence group $(\mathrm{n}=70 ;$ median age $=30 ; S D=4.9)$.

\subsection{Type of Study}

This is a descriptive, comparative, and interpretative study that seeks to detect differences in personality characteristics of a sample of offenders (homicide and domestic violence perpetrators).

\subsection{Procedure}

With appropriate consent and authorization from relevant authorities in the correctional facilities to conduct this study, inmates were interviewed in order to identify their characteristic personality traits and differences between groups. Protocols were completed voluntarily, and informed consent was given individually or in small groups, based on the availability of resources at the Center.

The Sociodemographic Questionnaire (CSD; for Mexican offenders and the Mexican population version [30] of the Minnesota Multiphasic Personality Inventory-2 [31] were administered [29]. Cut scores recommendations by [4] for working in correctional settings were followed to detect incomplete or random responding, particularly the validity scales VRIN (Variable Response Inconsistency), and TRIN (True Response Inconsistency), before the F (Infrequency), L (Lie), and K (Correction). Specifically, the initial sampling was originally composed by a total of 260 individuals who took the MMPI-2. Protocols were excluded on the basis of the following criteria: Cannot Say (?) scores equal to or greater than 30 items, and VRIN or TRIN scores $65 \mathrm{~T}$ through 79T (inclusive). Protocols having thus been "filtered", a total of 50 were excluded (39 offenders, and 11 non-offenders). All scores obtained were validated and interpreted in statistical analyses, with $\mathrm{T}$ scores as indicated by the Mexican version of the MMPI-2.

\subsection{Instruments}

Two tests were administered: the Sociodemographic Questionnaire (CSD; for Mexican offenders, which yielded significant independent variables related to main characteristics (age, schooling, offense and marital status), and the Mexican version of the Minnesota Multiphasic Personality Inventory-2 $[29,30,31]$, which yielded more than 40 personality-related variables of Mexican offenders.

\subsection{Ethical Considerations}

In order to follow research ethics, an approval was obtained at first from the ethics committee of Faculty of Psychology National Autonomous University of Mexico. In addition, the participants were given information about the goals and methodology of the study and asked to fill out and sign a form of written informed consent. The right of withdrawal from the study was explained to them. In addition, without any pressure or judgment, the informed consent of participants was obtained.

\section{Results}

Using a Student's t-test analysis, statistically significant differences between groups were found on the 43 MMPI-2 content, clinical, validity, and supplemental scales. When analyzing mean scale scores between the homicide offenders' group and domestic violence offenders' group, statistically significant differences were found $(\mathrm{p}<.05$ y $\mathrm{p}<.01)$.

Moreover, differences and effect size (Cohen's $d$ ) were examined for estimation. Using Cohen's $d$ for same-size groups, effect size was assigned on the basis of the following parameters, which were useful for interpretation and result analysis. The following criteria was used: $\mathrm{d}=\leq 0.2$ is defined as a small size effect; $d=>0.2$ but $\leq 0.5$ as a medium size effect; and $\mathrm{d}=>0.5$ but $\leq 0.8$ as a large size effect (ClarkCarter, 2004).

Table 1. Student's t-test for the MMPI-2 validity scales.

\begin{tabular}{llllllll}
\hline \multirow{2}{*}{ Scale } & \multicolumn{2}{l}{ Family violence $(\mathbf{n}=\mathbf{7 0})$} & \multicolumn{2}{l}{ Homicide Offenders $(\mathbf{n}=\mathbf{7 0})$} & Differences \\
\cline { 2 - 8 } & Mean & SD & Mean & SD & $\mathbf{t}_{(138)}$ & Sig. & d (Cohen) \\
\hline L Lie & 66 & 8.2 & 45 & 8.8 & 14.52 & $.001 * * *$ & $2.47^{\mathrm{a}}$ \\
F Infrequency & 48 & 9.4 & 61 & 11.3 & -6.98 & $.001 * * *$ & $-1.25^{\mathrm{a}}$ \\
K Correction & 60 & 7.7 & 43 & 7.4 & 13.48 & $.001 * * *$ & $2.25^{\mathrm{a}}$ \\
Variable Response Inconsistency (VRIN) & 50 & 8.3 & 51 & 7.3 & -.86 & .393 & -0.12 \\
True Response Inconsistency (TRIN) & 57 & 4.8 & 58 & 4.9 & -1.37 & .172 & -0.20 \\
Fp Infrequency & 49 & 8.5 & 59 & 9.6 & -6.73 & $.001 * * *$ & $-1.10^{\mathrm{a}}$ \\
\hline
\end{tabular}

Note: Scales with the (a) subscript indicate clinical relevance for differences due to uniform $\mathrm{T}$ scores falling out of the mean range (T45 - T55). $* \leq .05$; $* * \leq .01 ; * * * \leq .001$.

Statistically significant differences were found for both groups at a level of .001 (Table 1). In this sense, for domestic violence offenders, significant mean score elevations were seen on the $\mathrm{L}$ (Lie) and $\mathrm{K}$ (Correction) scales, while for homicide offenders significant mean score elevations were seen on the F (Infrequency) and Fp scales.

Based on the analysis using Cohen's d statistical test to measure effect size, four validity scales were found to have a 
large size effect, with a lower score on the $\mathrm{L}$ (Lie) and $\mathrm{K}$ (Correction) scales in the homicide offenders' group. Likewise, elevations on the $\mathrm{F}$ (Infrequency) and Fp (Infrequency-Psychopathology) scales can be seen in the same group. By contrast, the effect size for the Variable Response Inconsistency (VRIN) and True Response Inconsistency (TRIN) scales was small with no clinical relevance among groups.

Table 2. Student's t-test for the MMPI-2 clinical scales.

\begin{tabular}{|c|c|c|c|c|c|c|c|}
\hline \multirow{2}{*}{ Scale } & \multicolumn{2}{|c|}{ Family Violence $(n=70)$} & \multicolumn{2}{|c|}{ Homicide Offenders $(n=70)$} & \multicolumn{3}{|c|}{ Differences } \\
\hline & Mean & SD & Mean & SD & $\mathbf{t}_{(138)}$ & Sig. & D (Cohen) \\
\hline 1 Hypochondriasis (Hs) & 55 & 7.9 & 51 & 9.4 & 2.860 & $.005 * *$ & 0.46 \\
\hline 2 Depression (D) & 57 & 8.5 & 49 & 10.8 & 2.972 & $.003 * *$ & 0.51 \\
\hline 3 Hysteria (Hy) & 58 & 8.2 & 48 & 11.3 & 5.605 & $.001 * * *$ & $1.01^{\mathrm{a}}$ \\
\hline 4 Psychopathic Deviate (Pd) & 58 & 9.7 & 61 & 10.6 & -5.179 & $.001 * * *$ & $-0.88^{\mathrm{a}}$ \\
\hline 5 Masculinity/Femininity (Mf) & 50 & 8.4 & 49 & 11.8 & .552 & .582 & 0.09 \\
\hline 6 Paranoia $(\mathrm{Pa})$ & 57 & 9.9 & 63 & 10.5 & -2.640 & $.009 * *$ & $-0.39^{\mathrm{a}}$ \\
\hline 8 Schizophrenia (Sc) & 54 & 8.3 & 60 & 10.7 & -2.722 & $.007 * *$ & $-0.41^{\mathrm{a}}$ \\
\hline 9 Hypomania (Ma) & 46 & 7.8 & 62 & 12.0 & -9.661 & $.001 * * *$ & $-1.58^{\mathrm{a}}$ \\
\hline 0 Social Introversion $(\mathrm{Si})$ & 50 & 7.8 & 48 & 8.4 & 1.585 & .115 & 0.24 \\
\hline
\end{tabular}

Note: Scales with the (a) subscript indicate clinical relevance for differences due to uniform $\mathrm{T}$ scores falling out of the mean range (T45 - T55). $* \leq .05$; $* * \leq .01 ; * * * \leq .001$.

In Table 2, significant differences obtained at a level of .01 are reported, as well as a large effect size for the Depression (D), Hysteria (Hy), and Masculinity/Femininity (Mf) scales, showing lower scores on said scales in the homicide offenders' group. For the Hypochondriasis (Hs) and Social Introversion $(\mathrm{Si})$ scales, differences show a medium effect size that does not prove to be clinically significant in neither group. Similarly, effect size for the Psychasthenia $(\mathrm{Pt})$ scale is small.

Nevertheless, the Psychopathic Deviate (Pd) and the Hypomania (Ma) scales show a large effect size suggesting a clinically significant elevation in relation to differences in the homicide group. Similarly, differences indicate clinical relevance of the Paranoia $(\mathrm{Pa})$ and the Schizophrenia $(\mathrm{Sc})$ scales in the same group, despite having a medium effect size.

Table 3. Student's t-test for the MMPI-2 content scales.

\begin{tabular}{|c|c|c|c|c|c|c|c|}
\hline \multirow{2}{*}{ Scale } & \multicolumn{2}{|c|}{ Family Violence $(n=70)$} & \multicolumn{2}{|c|}{ Homicide offenders $(n=70)$} & \multicolumn{3}{|c|}{ Differences } \\
\hline & Mean & SD & Mean & SD & $\mathbf{t}_{(138)}$ & Sig. & d (Cohen) \\
\hline Anxiety (ANX) & 46 & 7.1 & 55 & 9.3 & -6.73 & $.001 * * *$ & -1.08 \\
\hline Fears (FRS) & 51 & 9.6 & 54 & 10.7 & -1.34 & .183 & -0.29 \\
\hline Obsessiveness (OBS) & 44 & 6.0 & 56 & 8.0 & -10.40 & $.001 * * *$ & $-1.69^{\mathrm{a}}$ \\
\hline Depression (DEP) & 48 & 8.9 & 59 & 9.3 & -6.85 & $.001 * * *$ & $-1.20^{\mathrm{a}}$ \\
\hline Health Concerns (HEA) & 50 & 8.7 & 56 & 10.2 & -3.89 & $.001 * * *$ & $-0.63^{\mathrm{a}}$ \\
\hline Bizarre Mentation (BIZ) & 55 & 7.6 & 63 & 9.8 & -11.09 & $.001 * * *$ & $-1.94^{\mathrm{a}}$ \\
\hline Cynicism (CYN) & 57 & 8.0 & 59 & 9.5 & -10.14 & $.001 * * *$ & $-1.70^{\mathrm{a}}$ \\
\hline Antisocial Practices (ASP) & 41 & 6.5 & 63 & 10.9 & -14.61 & $.001 * * *$ & $-2.45^{\mathrm{a}}$ \\
\hline Type A (TPA) & 40 & 5.2 & 53 & 7.7 & -12.15 & $.001 * * *$ & -1.97 \\
\hline Low Self-Esteem (LSE) & 43 & 6.7 & 52 & 7.8 & -7.36 & $.001 * * *$ & -1.23 \\
\hline Social Discomfort (SOD) & 48 & 7.4 & 49 & 8.4 & -.15 & .881 & -0.12 \\
\hline Family Problems (FAM) & 59 & 7.0 & 56 & 8.3 & -10.05 & $.001 * * *$ & $-1.69^{\mathrm{a}}$ \\
\hline Work Interference (WRK) & 45 & 6.7 & 56 & 7.3 & -9.42 & $.001 * * *$ & $-1.57^{\mathrm{a}}$ \\
\hline
\end{tabular}

Note: Scales with the (a) subscript indicate clinical relevance for differences due to uniform $\mathrm{T}$ scores falling out of the mean range (T45 - T55). $* \leq .05$; $* * \leq .01 ; * * * \leq .001$.

Scores on the content scales (Table 3) show statistically significant differences at a level of .001 only in the homicide offenders' group. Cohen's $d$ test-based analysis demonstrated that thirteen scales out of the fifteen comprising the profile have a large size effect, with a score elevation in the homicide offenders' group.

In this sense, the following scales have a large effect size implying that clinically significant differences exist: Obsessiveness (OBS), Depression (DEP), Health Concerns (HEA), Bizarre Mentation (BIZ), Anger (ANG), Cynicism
(CYN), Antisocial Practices (ASP), Family Problems (FAM), and Work Interference (WRK). By contrast, the Anxiety (ANX), the Type A (TPA), the Low Self-Esteem (LSE), and the Negative Treatment Indicators (TRT) scales also show a large effect size. However, such effect does not indicate any clinically significant difference in both groups.

The Fears (FRS) scale has a medium effect size, while the Social Discomfort (SOD) scale has a small effect size. These scores show that neither scale indicates a significant difference in scores obtained in the two groups. 
Table 4. Student's t-test for the MMPI-2 supplemental scales.

\begin{tabular}{|c|c|c|c|c|c|c|c|}
\hline \multirow{2}{*}{ Scale } & \multicolumn{2}{|c|}{ Family violence $(n=70)$} & \multicolumn{2}{|c|}{ Homicide offenders $(n=70)$} & \multicolumn{3}{|c|}{ Differences } \\
\hline & Mean & SD & Mean & SD & $\mathbf{t}_{(138)}$ & Sig. & d (Cohen) \\
\hline Anxiety (A) & 45 & 5.6 & 56 & 8.2 & -9.68 & $.001 * * *$ & $-1.56^{\mathrm{a}}$ \\
\hline Repression (R) & 62 & 7.8 & 42 & 7.9 & 15.51 & $.001 * * *$ & $2.54^{\mathrm{a}}$ \\
\hline Ego Strength (Es) & 49 & 7.1 & 43 & 9.8 & 4.02 & $.001 * * *$ & 0.70 \\
\hline MacAndrew Alcoholism (MAC) & 38 & 3.4 & 74 & 3.8 & -59.01 & $.001 * * *$ & $-10^{\mathrm{a}}$ \\
\hline Over-Controlled Hostility $(\mathrm{OH})$ & 61 & 6.5 & 47 & 10.7 & 9.16 & $.001 * * *$ & $1.58^{\mathrm{a}}$ \\
\hline Dominance (Do) & 53 & 8.1 & 40 & 8.6 & 9.09 & $.001 * * *$ & 1.55 \\
\hline College Maladjustment (Mt) & 45 & 6.9 & 56 & 9.4 & -7.96 & $.001 * * *$ & $-1.33^{\mathrm{a}}$ \\
\hline Masculine Gender (GM) & 47 & 9.9 & 44 & 11.4 & 2.10 & $.04 *$ & 0.28 \\
\hline Feminine Gender (GF) & 54 & 6.3 & 37 & 10.7 & 11.96 & $.001 * * *$ & 1.93 \\
\hline Posttraumatic Stress Disorder (PK) & 46 & 7.0 & 60 & 10.3 & -9.84 & $.001 * * *$ & $-1.59^{\mathrm{a}}$ \\
\hline Posttraumatic Stress Disorder (PS) & 45 & 6.3 & 58 & 9.9 & -9.34 & $.001 * * *$ & $-1.56^{\mathrm{a}}$ \\
\hline
\end{tabular}

Note: Scales with the (a) subscript indicate clinical relevance for differences due to uniform $\mathrm{T}$ scores being higher than the mean range (T45 - T55). $* \leq .05$; $* * \leq .01 ; * * * \leq .001$

Statistically significant differences were found at a level of .001 between both groups, as shown in Table 4 . The scales with a large effect size and a score elevation and clinically significant differences in the homicide offenders' group are Anxiety (A), MacAndrew Alcoholism Scale (Mac-R), College Maladjustment (Mt), Post-Traumatic Stress Disorder - Keane (PK), and Post-Traumatic Stress Disorder Schlenger (PS). Similarly, Repression (R), Ego Strength (Es), Overcontrolled Hostility (OH), Dominance (Do), Social Responsibility (Re), and Gender Role - Feminine (GF) have a large effect size. However, this implies lower scores on said scales in the same group. Differences and lower scores yield clinically relevant elements that are analyzed and interpreted based on the characteristics of each scale and the effect on a group's behavior.

The effect size for the Gender Role - Masculine scale is medium, but this does not indicate clinical relevance in neither group.

\section{Discussion}

The results obtained by administering the MMPI-2 to a group of homicide and domestic violence offenders for this study describe elevations on the scales that measure aggressiveness. Likewise, it is noticeable how elevations on different MMPI-2 scales are associated aggressiveness and violent behavior.

The scale that manifest these differences in the domestic violence offenders' group is Lie (L), which based on the obtained score, describes normal people who have a critical moral attitude and a need to create a favorable impression in order to avoid difficulties and problems. The Correction (K) scale indicates a tendency to act in a defensive way and difficulties to acknowledge problems.

Similar studies on MMPI-2-based psychological assessment by Bustos de la Tijera, Ampudia, Jiménez \& Nájera [32] have reported that profiles of violence perpetrators show elevations on the $\mathrm{L}$ scale, which is indicator of persons who tend to show a positive image, reliability, moralism, the capacity to assume responsibility, and appropriate control of aggression. However, this population tend to show defensive responding on psychological tests with the purpose of creating a favorable impression. Such was the case of the domestic violence offenders' group.

Positive correlations on scales associated with aggressive behavior were found together with traits related to paranoia, hysteria, hypochondriasis, psychasthenia, and schizophrenia in the domestic violence perpetrators group. These findings are supported by previous studies [32] on aggressive behavior, as they overlapped with reported results of elevations on the paranoia and schizophrenia scales Authors explain that this population usually shows anger and resentment, they tend to be hostile and often feel attacked. The same characteristics are present in homicide offenders [33].

This behavior expressed by the family aggression and family group is related to a set of interiorized ideas, such as not only feeling superior to women but also embracing insecurity, confusion, frustration that in time will materialize in the form of screams, insults, and blows. These men can be seductive and persuasive but show high levels of dependency and low self-esteem. They deny violence and are usually insecure, jealous, dominant, and aggressive, and show sexist attitudes [34].

They are controlling and dominant, and adopt severe, inflexible attitudes, and tend to make decisions unilaterally (without taking others into account). They may have substance abuse problems and show self-destructive behaviors, and harass, insult, threaten, and throw or break objects. Emotionally, they show significant affective inhibition and accumulation of unexpressed emotional affective states. Great frustration, depression, selfdepreciation, and ideas of hopelessness or helplessness are exhibited. [34].

Cognitively, they minimize consequences, have high expectations of others, do not define or acknowledge their behavior as violent, believe that others provoke their reactions, justify their behavior in order to correct or educate, think that they must be obeyed by persons with less authority, and imagine negative situations and perceive themselves as being adversely affected [35]. 
Behavioral aspects include public-private behavior dissociation, impulsivity, isolation, possessive attitudes, dependent behaviors, and inappropriate decision expression [36].

Violent persons show facets varying from silence to ranting, from flight to confrontation; those who on the receiving end of violence may be rejected, ignored, or socially attacked, psychologically or physically, being morally or bodily damaged [37].

\section{Conclusion}

The phenomenon of violence becomes real in everyday life for human beings, and it is precisely within family that it is originated and perpetuated. In fact, family is not only affected by social violence, but reproduces at its core specific forms of violence commonly known as "abuse," which are not sufficiently acknowledged or examined in their real dimensions and deep relations with other types of violence, individual and social consequences, and how they contribute to the pervasive situation of violence.

On the other hand, for the homicide offenders' group, a decrease on the Lie (L) scale can be seen, suggesting characteristics opposed to domestic violence offenders, i.e., sarcastic persons with difficulties to adapt to social norms and tend to remove inhibitions easily.

By contrast, for the homicide offenders' group, the statistically significant scales based on scores that indicate clinical relevance are: Hypomania (Ma), Psychopathic Deviate (Pd), Paranoia ( $\mathrm{Pa})$, and Schizophrenia (Sc). These scales describe leery and untrusting individuals that easily attribute clear harmful intentions to others, as they feel other are against them. They tend to act in a defensive way in any situation without weighing the consequences of their actions, which is characteristic of impulsive subjects that are unable to control emotions. Moreove, they have difficulties obeying/following rules or orders and are manipulative individuals that seek to meet their needs over others and show hostile or aggressive behaviors when they fail. They show poor judgement capacity and altered perception of reality, so they usually misinterpret social situations.

Their offenses are reactions to stressful and tense individual experiences. This explanation supports that there exist a relation between tense experiences and proneness to committing a violent offense. In this approach, many violent offenses, such as homicides and domestic violence, are committed by persons experiencing feelings of anger, revenge, appetite for sex or money, and disdain for others.

In psychological terms, this criminal behavior indicates the interaction between factors such as thoughts and choices, emotions, rewards, traits, and personality profiles, learning and socialization processes, beliefs and attitudes, attributions and expectations. Consequently, it is important to consider the origin of antisocial or criminal behavior in a multifactorial way, which has not a single explanation. On the contrary, every explanation must be conceptualized as complementary to each other.

Individual characteristics and traits that predispose towards crime indicate the existence of certain biological and psychological characteristics that make people inclined to express antisocial or criminal behaviors. Some psychological characteristics have also been associated with criminal behavior, such as low intelligence, hyperactivity, high impulsivity, thrill seeking, low empathy, high extroversion, and external locus of control.

\section{Acknowledgements}

Supported by the project PAPIME No. PE304716 Autonomous National University of Mexico.

\section{References}

[1] Blackburn, R. (1998) Criminality and the interpersonal circle in mentally disordered offenders. Criminal justice and $\begin{array}{lrrr}\text { behavior. } & 25 & \text { (2), } & \text { 154-176. }\end{array}$ doi.org/10.1177/0093854898025002001.

[2] Tocaven, R. (1990) Psicología Criminal. México, Instituto Nacional de Ciencias Penales.

[3] Azoh, J. (2003). Maltrato familiar y búsqueda de ayuda formal en un grupo considerado no vulnerable. Un estudio de casos de hombres en el área metropolitana de Monterrey, N. L. en: René Landero (coord.), Familia: poder, violencia y género, Trillas, Monterrey, N.L.

[4] Megargee, E. I. (2006a). Use of the MMPI-2 in correctional settings. In J.N. Butcher, MMPI-2. A practitioner's guide (pp. 327-360). American Psychologycal Association, Wasington, DC. doi.org/10.1037/11287-019.

[5] Hathaway, S. R., \& MacKinley, J. C. (1943). The Minnesota Multiphasic Schedule. Minneapolis: University of Minnesota Press.

[6] Capwell, D. F. (1945). Personality patters of adolescent girls, II. Delinquents and nondelinquents. Journal of Applied Psychology, 29, 284-297. doi.org/10.1037/h0054701.

[7] Fry, F. D. (1949). A study of the personality traits of college students and of state prison inmates as measured by the MMPI The Journal of Psychology, 28, 439-449. doi.org/10.1080/00223980.1949.9916021.

[8] Hathaway, S. R. \& Monachesi, E. D. (1963). Adolescent personality and behavior. Minneapolis: University of Minnesota Press.

[9] Megargee, E. I. (1977). A new classification system for criminal offenders: I. The need for a new classification system. Criminal Justice and Behavior, 4, 107-114.

[10] Megargee, E. I., \& Bohm, M. J. Jr. (1979). Classifying criminal offenders: a new system based on the MMPI. Beverly Hills, CA: Sage.

[11] Megargee, E. I. (1994). Using the Megargee MMPI-based classification system with the MMPI-2s of male prison inmates. Psychological Assessment, 6, 337-344. doi.org/10.1037/1040-3590.6.4.337. 
[12] Megargee, E. I., Carbonell, J. L., Bohm, M. B., Jr., \& Sliger, G. L. (2001). Classifiying criminal offenders with MMPI-2: the Megargee System. Miniapolis: University of Minnesota Press.

[13] Megargee, E. I. (2000). User's guide for the MMPI-2. Criminal Justice and Correctional Report for Men. Minneapolis: University of Minnesota Press.

[14] Anno, B. J. (1991). Prison health care: Guidelines for tehe management of an adequate delivery system. Chicago: National Commission on Correctional Health Care.

[15] Beck, A. J., \& Maruschak, L. (2001). Mental health treatment in state prisons 2000 (Bureau of Justice Statistics Special Reports). Washington, DC: Office of Justice Programs, Bureau Of Justice Statistics, U. S. Department of Justice.

[16] Ditton, P. J. (1999). Mental health and treatment of inmates and probationers (Bureau of Justice Statistics Special Report). Washington, DC: Office of Justice Programs, Bureau of Justice Statistics, U. S. Department of Justice.

[17] Mumola, C. J. (1999). Substance abuse and treatment, state and federal prisoners, 1997 (Bureau of Justice Statistics Special Report). Washington, DC: Office of Justice Programs, Bureau of Justice Statistics, U.S. Department of Justice.

[18] Megargee, E. I. (2006b). Using the MMPI-2 in criminal justice and correctional settings. Minneapolis: University of Minnesota Press. doi: 10.1037/0022-006X.53.6.874.

[19] Ampudia, A., Sánchez, G., Jiménez, F. Pérez, J. \& Rovelo, N. (2018). La violencia intrafamiliar: maltrato a la mujer y a los hijos. Revista Sociedad Española de Psicología Jurídica y Forense (SEPJF) 11 (1), 375-377. ISBN970-84-949379-7-2.

[20] Hathaway, S. R.; McKinley, J. C. (1967) Minnesota Multiphasic Personality lnventory (New York, Harcourt Brace Jovanovich) (trad. esp.: Madrid, I'EA Ediciones S. A., 1981).

[21] Butcher, J. N. Hess, G. A., Greene, R. L. \& Nelson, L. D. (2015). Using the MMPI-2 in Forensic Assessment. American Psychological Association

(APA). https://doi.org/10.1037/14571-000.

[22] Butcher, J. N. (2013). 25 Highlights of Using the MMPI/MMPI-2 with Criminal Offenders. Retrieved from. Recuperado de http://www. umn.edu/mmpi.

[23] Jones, T., Beidleman, W.B. \& Fowler, R.D. (1981). Differentiating violent and nonviolent prison inmates by use of selected MMPI scales. Journal of Clinical Psychology, 37(3), 673-678. doi: 10.1002/1097.

[24] Boscan, D. C., Penn, N. E., Velásquez, R. J., Savino, A. V., Maness, P., Guzman, M. et al. (2002). MMPI-2 performance of mexican male university student and prison inmutes. Journal of clinical psychology, 58, 465-470.
[25] Megargee, E. I., Mercer, S. J., \& Carbonell, J. L. (1999). MMPI-2 with male and female state and federal prison inmates. Psychological Assessment, 11 (2), 177-185.

[26] Panton, J. H. (1959). The response of prison inmates to seven new MMPI scales. Journal of Clinical Psychology, 15, 196197. http: // dx.doi.org/10.1002/1097.

[27] Panton, J. H. (1962). The identification of habitual criminalist with the MMPI. Journal of Clinical Psychology, 2, 133-136. http: // dx.doi.org/10.1002/1097.

[28] Oliver, W. \& Mosher, D. (1968). Psychopathology and guilt in heterosexual and subgroups of homosexual reformatory inmates. Journal of Abnormal Psychology, 73, 323-329. http://dx.doi. org/10.1037/h0026115.

[29] Ampudia, A. (en prensa). Cuestionario sociodemográfico del delincuente mexicano. Universidad Nacional Autónoma de México (UNAM). Facultad de Psicología. México, DF.

[30] Butcher, J. R. Graham, Y. S. Ben-Porath, A. Tellegen, W. G. Dahlstrom y B. Kaemmer (1989). Minnesota Multiphasic Personality Inventory- (MMPI-2): Manual for.

[31] Lucio, E., Reyes-Lagunes, I., \& Scott, R. D. (1994). MMPI-2 for Mexico: Translation and adaptation. Journal of Personality Assessment, 63, 105-116. doi.org/10.1207/s15327752jpa6301_9.

[32] Bustos T.L, Ampudia, R.A, Jiménez G. y Nájera M.I, (2012) Evaluación del riesgo de Violencia en agresores de mujeres. Revista Mexicana de Psicología. Memoria in extenso.

[33] González R., P.; Sánchez, M. G.; Ampudia R., A.; Jiménez, J. G., (2017). La precisión diagnóstica del MMPI-2 al evaluar los desajustes socio-familiares en personas con dependencia de sustancias. Clínica y Salud. 28/2, pp. 53 - 57.

[34] Ampudia, A., Sánchez, G., \& Jiménez, F. (2018). La contribución del MMPI-2 a la predicción del riesgo de violencia. Revista de psicología, (PUCP), 36 (2), 603-629. (ISSN 0254-9247). https://doi.org/10.18800/psico.201 802.008.

[35] Zavaleta B. J. A., (2018). Elementos para la construcción del concepto de campo de la violencia. Revista Sociológica (Méx.) 33(93) México versión On-line ISSN 2007-8358versión impresa ISSN 0187-0173.

[36] Bailey, J., (2014). Crimen e impunidad. Las trampas de la seguridad en México. México: Debate. http://www.scielo.org.mx/scielo.php?script=sci_nlinks\&pid=S 0187-0173201800010015100006\&lng

[37] Jiménez, G. F., Sánchez, C. G \& Ampudia, R. A. (2016). 